\title{
TEORES DE NUTRIENTES NA ALFACE IRRIGADA COM ÁGUA RESIDUÁRIA APLICADA POR SISTEMAS DE IRRIGAÇÃO
}

\author{
DELVIO SANDRI ${ }^{1}$, EDSON E. MATSURA ${ }^{2}$, ROBERTO TESTEZLAF $^{3}$
}

RESUMO: Desenvolveu-se este trabalho para avaliar a composição química da parte aérea da alface, cv. Elisa, irrigada com água residuária tratada com leitos cultivados com macrófitas e água de um depósito de fonte hídrica superficial, cultivada em Latossolo Vermelho Distroférrico, utilizando-se dos sistemas de irrigação por aspersão convencional, gotejamento subterrâneo e superficial. O experimento compreendeu o período de 17-8 a 3-10-2001, e as análises químicas da alface foram realizadas aos 47 dias após o transplantio das mudas em campo. A parte aérea da alface foi analisada quanto ao teor de nitrogênio total, nitrato, fósforo, potássio, cálcio, magnésio, enxofre, ferro, manganês, cobre, zinco, sódio, boro, cobalto e molibdênio. O sódio e o enxofre apresentaram teores maiores que o máximo adequado na parte aérea da alface e o magnésio menor, enquanto para os demais elementos químicos foram normais e adequados, considerando os padrões para plantas bem nutridas, não sendo influenciados pelo tipo de água. O sódio foi o elemento químico que apresentou a maior elevação na parte aérea nos tratamentos irrigados com água residuária, apresentando diferença significativa em relação à água do depósito superficial nos três sistemas de irrigação. A utilização dos diferentes sistemas de irrigação para aplicação de água residuária tratada com leitos cultivados com macrófitas não interferiu no teor de nutrientes na parte aérea.

PALAVRAS-CHAVE: Lactuca sativa L., aspersão, gotejamento.

\section{NUTRIENTS LEVELS IN LETTUCE IRRIGATED WITH WASTEWATER APPLIED BY IRRIGATION SYSTEMS}

ABSTRACT: A trial was carried out to evaluate the chemical composition in the aerial part of lettuce, cv. 'Elisa', irrigated with wastewater treated with constructed wetland and source deposit water, grown on a Rhodic Hapludox Soil, using the irrigation systems sprinkle, subsurface drip and surface drip irrigation. The experiment was carried out from August $17^{\text {th }}$ to October $3^{\text {rd }}$ of 2001 and the chemical analyses of the lettuce were accomplished to 47 days after transplanting of the seedling. The aerial part of the lettuce was analyzed as for the levels of total nitrogen, nitrate, phosphorus, potassium, calcium, magnesium, sulfur, iron, manganese, copper, zinc, sodium, boron, cobalt and molybdenum. The sodium and the sulfur presented higher levels than the maximum suitable in the aerial part of the lettuce and the smallest level of magnesium, while other chemical elements analyzed were normal and appropriate considering the standard for well-nourished plants, not being influenced by the water type. The sodium was the chemical element that presented the highest levels in the aerial part of the lettuce in the treatments irrigated with wastewater, presenting significant difference in relationship to the treatments irrigated with source deposit water in the three irrigation systems. The use of the different irrigation systems by the application of wastewater treated with constructed wetland did not interfere in the levels of nutrients in the aerial part of the lettuce.

KEYWORDS: Lactuca sativa L., sprinkle, drip.

\footnotetext{
${ }^{1}$ Eng ${ }^{o}$ Agrícola, Docente de Ensino Superior IV, Faculdade de Engenharia Agrícola, Universidade Estadual de Goiás, BR 153, km 98, Cx. Postal 459, Anápolis - GO, Fone: (0XX62) 3328.1160, sandri@ueg.br

${ }^{2}$ Eng ${ }^{\mathrm{o}}$ Agrônomo, Prof. Livre Docente, FEAGRI/UNICAMP, Campinas - SP, matsura@ agr.unicamp.br

${ }^{3}$ Eng ${ }^{\mathrm{o}}$ Agrícola, Prof. Titular, FEAGRI/UNICAMP, Campinas - SP, bob@ agr.unicamp.br

Recebido pelo Conselho Editorial em: 15-3-2005

Aprovado pelo Conselho Editorial em: 14-12-2005
} 


\section{INTRODUÇÃO}

A utilização de efluentes na agricultura cresceu consideravelmente nos últimos anos em muitos países, inclusive no Brasil; no entanto, ainda não foram suficientemente estudados todos os aspectos positivos e negativos dessa técnica, especialmente sobre as propriedades físicas e químicas do solo, absorção de nutrientes pelas plantas ou sua toxidez. Dentre os principais fatores que vieram a contribuir para que, nos últimos anos, aumentasse o interesse pela irrigação com efluentes, estão a escassez de recursos hídricos, o avanço do conhecimento técnico-científico, a legislação ambiental mais rigorosa e atuante, o maior controle da poluição ambiental, com redução de problemas à saúde humana e animal, a diminuição dos custos de tratamento devido à atuação do solo como forma de disposição e fornecimento de nutrientes e matéria orgânica às plantas, reduzindo os custos com fertilizantes químicos comerciais (SANDRI, 2003).

Em geral, os esgotos domésticos apresentam teores de macro e micronutrientes suficientes para o atendimento da demanda da maioria das culturas, podendo apresentar de 200 a $400 \mathrm{mg} \mathrm{L}^{-1}$ de sais e $300 \mathrm{mg} \mathrm{L}^{-1}$ de sólidos dissolvidos inorgânicos (BOUWER, 1992). Os efluentes municipais são importante fonte de fertilizantes para a agricultura, melhorando o rendimento das culturas, porém devem ser consideradas as exigências nutricionais de cada cultura e o tipo de solo do local, ainda durante o planejamento da irrigação com efluente. $\mathrm{O}$ nitrogênio, o fósforo e a matéria orgânica no efluente tratado agem como fertilizantes e como condicionadores de solo, favorecendo o desenvolvimento das plantas (FASCIOLO et al., 2002).

O nitrogênio e o potássio são os nutrientes mais exigidos pelas culturas, necessitando de doses elevadas nas adubações e isso, particularmente com relação ao nitrogênio, tem trazido preocupação sob dois aspectos: o primeiro, pela contaminação de águas subterrâneas e dos mananciais, e o segundo, pela elevação dos teores de nitrato $\left(\mathrm{NO}_{3}{ }^{-}\right)$nos alimentos, principalmente naqueles de consumo in natura, como as hortaliças e frutas. $\mathrm{O} \mathrm{NO}_{3}{ }^{-}$absorvido pelas raízes é reduzido a $\mathrm{NH}_{4}{ }^{+}$, sendo essa redução e o conseqüente acúmulo de nitrato nas plantas, afetados por diversos fatores, como os genéticos e ambientais, especialmente a intensidade luminosa que, quando for baixa, pode reduzir o acúmulo de nitrato e o sistema de cultivo (convencional, orgânico e hidropônico) (FAQUIN, 2004, e MIYAZAWA et al., 2001).

Dessa forma, este trabalho foi realizado para avaliar o teor de nutrientes da parte aérea da alface irrigada com água residuária tratada com leitos cultivados com macrófitas e água de um depósito de fonte hídrica superficial, utilizando a aspersão, o gotejamento subterrâneo e o superficial.

\section{MATERIAL E MÉTODOS}

O estudo foi desenvolvido no Campo Experimental da Faculdade de Engenharia Agrícola da Universidade Estadual de Campinas (FEAGRI/UNICAMP). O solo foi classificado como Latossolo Vermelho Distroférrico. O clima, segundo a classificação de Köeppen, é uma transição entre Cwa e Cwf, isto é, subtropical de altitude, seco no inverno e chuvoso e quente no verão, com precipitação média anual em torno de $1.370 \mathrm{~mm}$, temperatura média anual de $21,7^{\circ} \mathrm{C}$ e umidade relativa do ar de $66,2 \%$.

O delineamento experimental utilizado foi em esquema fatorial, com três sistemas de irrigação (aspersão, gotejamento subterrâneo e superficial) x dois tipos de água (residuária e de um depósito de fonte hídrica superficial), com três repetições. Os tratamentos utilizados foram: Ar - aspersão utilizando água residuária; Ad - aspersão utilizando água do depósito; GbR - gotejamento subterrâneo utilizando água residuária; GbD - gotejamento subterrâneo utilizando água do depósito; GpR gotejamento superficial utilizando água residuária, e $\mathrm{GpD}$ - gotejamento superficial utilizando água do depósito. 
A água utilizada na Faculdade de Engenharia Agrícola/UNICAMP é fornecida pela Companhia de Abastecimento de Água de Campinas (SANASA) e também por poços artesianos localizados no interior da Universidade, e o esgoto gerado é lançado na rede coletora local. Esse esgoto é composto de mistura de dejetos domésticos e sanitários dos vários laboratórios, dos prédios de sala de aula e de administração, cozinha, cantina e água de lavagem da oficina mecânica.

O efluente foi tratado por um reator anaeróbio compartimentado, composto de três caixas de cimento amianto em série de 1.000; 500 e $500 \mathrm{~L}$, passando em seguida por seis leitos de formato retangular e quadrado, dispostos em paralelo, preenchidos com brita número dois e área de $4 \mathrm{~m}^{2}$ cada leito, cultivados com macrófitas enraizadas e emergentes Typha spp (taboa) e Eleocharis spp (junco manso), com vazão subsuperficial e tempo de retenção hidráulica de cerca de 5 dias. Demais detalhes construtivos podem ser obtidos em VALENTIM (2003). O efluente, após o tratamento, foi armazenado em um reservatório com capacidade para $15.000 \mathrm{~L}$, para posterior utilização na irrigação.

A água utilizada no tratamento-testemunha foi captada de um reservatório existente na própria Faculdade de Engenharia Agrícola, abastecido por bombeamento, de um reservatório a céu aberto.

As coletas da água residuária e do depósito de fonte hídrica superficial para análise química foram realizadas aos 10; 25 e 47 dias após o transplantio (DAT) das mudas de alface para o campo. Para cada data de amostragem, coletou-se uma amostra de água na saída dos bocais dos aspersores e outra logo após a passagem pelos filtros do sistema de irrigação por gotejamento, analisados separadamente, e posteriormente efetuada a média aritmética. As amostras de água foram acondicionadas em garrafas de vidro transparente esterilizadas, próprias para coleta, com volume total de $250 \mathrm{~mL}$ e posteriormente armazenadas a $4{ }^{\circ} \mathrm{C}$, conforme indicado por APHA/AWWA/WPCF (1995).

Os parâmetros analisados na água residuária e do depósito superficial (Tabela 1) foram sódio $(\mathrm{Na})$, cálcio $(\mathrm{Ca})$, magnésio $(\mathrm{Mg})$, razão de absorção de sódio (RAS), enxofre (S), ferro (Fe), boro (B), potássio $(\mathrm{K})$, fósforo $\left(\mathrm{P}\right.$ e $\left.\mathrm{P}_{2} \mathrm{O}_{5}\right)$, nitrogênio $\left(\mathrm{N}-\mathrm{NH}_{4}{ }^{+}\right.$e $\left.\mathrm{N}-\mathrm{NO}_{3}{ }^{-}\right)$, demanda bioquímica de oxigênio (DBO), conforme descrito em APHA/AWWA/WPCF (1995) e HACH (1997), condutividade elétrica (EC), determinada com um condutivímetro marca Digimed DM 31, e pH determinado por um peagômetro, marca Tecnal, modelo Tec - $3 \mathrm{MP}$.

TABELA 1. Qualidade da água utilizada na irrigação por aspersão, gotejamento subterrâneo e superficial analisada aos 10; 25 e 47 dias após o transplantio da alface em campo.

\begin{tabular}{|c|c|c|c|c|c|c|}
\hline \multirow{3}{*}{ Parâmetros } & \multicolumn{3}{|c|}{ Água Residuária } & \multicolumn{3}{|c|}{ Água do Depósito } \\
\hline & 10 & 25 & 47 & 10 & 25 & 47 \\
\hline & \multicolumn{6}{|c|}{ - } \\
\hline$\overline{\mathrm{S}}$ & 2,5 & 3,0 & 4,0 & 1,0 & 1,0 & 2,5 \\
\hline $\mathrm{Fe}$ & 1,1 & 0,8 & 0,5 & 0,4 & 0,9 & 0,9 \\
\hline B & ALD & 0,1 & 0,1 & ALD & ALD & 0,3 \\
\hline $\mathrm{P}$ & 1,55 & 2,35 & 1,45 & 0,12 & 0,02 & 0,13 \\
\hline $\mathrm{P}_{2} \mathrm{O}_{5}$ & 3,41 & 5,35 & 1,83 & 0,27 & 0,05 & 0,32 \\
\hline $\mathrm{N}-\mathrm{NH}_{4}^{+}$ & 36,1 & 32,5 & 37,4 & 0,0 & 0,0 & 0,0 \\
\hline $\mathrm{N}-\mathrm{NO}_{3}^{-}$ & 0,8 & 1,2 & 0,3 & 0,3 & 0,4 & 0,2 \\
\hline $\mathrm{DBO}_{5}$ & 23 & 53 & 5 & 15 & 40 & 0 \\
\hline $\mathrm{K}\left(\mathrm{meq} \mathrm{L}^{-1}\right)$ & 0,23 & 0,28 & 0,31 & 0,01 & 0,01 & 0,03 \\
\hline $\mathrm{Na}\left(\mathrm{meq} \mathrm{L}^{-1}\right)$ & 0,78 & 0,84 & 0,80 & 0,09 & 0,09 & 0,04 \\
\hline $\mathrm{Ca}\left(\mathrm{meq} \mathrm{L}^{-1}\right)$ & 1,42 & 1,50 & 1,53 & 0,23 & 0,18 & 0,20 \\
\hline $\operatorname{Mg}\left(\right.$ meq L $\left.{ }^{-1}\right)$ & 0,21 & 0,16 & 0,25 & 0,17 & 0,17 & 0,17 \\
\hline $\operatorname{RAS}\left(\mathrm{mmol}_{\mathrm{c}} \mathrm{L}^{-1}\right)^{1 / 2}$ & 0,86 & 0,92 & 0,85 & 0,20 & 0,21 & 0,10 \\
\hline $\left.\mathrm{EC}(\mathrm{dS} \mathrm{m})^{-1}\right)$ & 0,52 & 0,52 & 0,63 & 0,06 & 0,05 & 0,05 \\
\hline $\mathrm{pH}$ & 7,2 & 7,4 & 7,4 & 6,9 & 7,1 & 6,9 \\
\hline
\end{tabular}

ALD - Abaixo do limite de detecção. 
Cada canteiro (unidade experimental) tinha as dimensões de 1,20 m de largura, 10,0 m de comprimento e 0,2 m de altura. Em cada canteiro, foram instaladas duas linhas de gotejadores modelo CarboDrip, com espaçamento entre os gotejadores de $0,4 \mathrm{~m}$ e vazão nominal de $2,3 \mathrm{~L} \mathrm{~h}^{-1}$ na pressão de $98 \mathrm{kPa}$. Na irrigação subterrânea, as linhas de gotejadores foram enterradas à profundidade de $0,1 \mathrm{~m}$ da superfície do solo. Na irrigação por aspersão, foram instalados quatro aspersores setoriais espaçados de $12,0 \times 12,0 \mathrm{~m}$ e vazão de $0,45 \mathrm{~m}^{3} \mathrm{~h}^{-1}$.

$\mathrm{Na}$ construção dos canteiros, foram incorporados na camada de 0-0,2 m, $33 \mathrm{~kg} \mathrm{ha}^{-1} \mathrm{de} \mathrm{N}$; $116 \mathrm{~kg} \mathrm{ha}^{-1}$ de $\mathrm{P}_{2} \mathrm{O}_{5}$, e $67 \mathrm{~kg} \mathrm{ha}^{-1}$ de $\mathrm{K}_{2} \mathrm{O}$, conforme TRANI \& RAIJ (1997). Também foram incorporados $20.800 \mathrm{~kg} \mathrm{ha}^{-1}$ de condicionador de solo à base de turfa (Solomax), contendo matéria orgânica, nitrogênio e magnésio em sua composição e condutividade elétrica, determinada pelo extrato aquoso turfa:água 1:2 (uma parte de turfa seca ao ar, para duas partes de água destilada base volume) entre 0,5 e 1,3 $\mathrm{dS} \mathrm{m}^{-1}$ e $\mathrm{pH}$ entre 5,5 e 6,2. Em cobertura, foram aplicados, por vez, $150 \mathrm{~kg} \mathrm{ha}^{-1} \mathrm{de} \mathrm{N}$ na forma de sulfato de amônio $(20 \%$ de N) aos 10; 20 e 32 dias após o transplantio (DAT), em todos os tratamentos.

As características químicas do solo do local do experimento antes do início da irrigação são apresentadas na Tabela 2.

TABELA 2. Valores médios das características químicas do solo do local do experimento.

\begin{tabular}{|c|c|c|c|c|c|c|c|c|c|c|c|c|c|}
\hline pH & $\mathrm{P}$ & $\mathrm{S}$ & K & $\mathrm{Na}$ & $\mathrm{Ca}$ & $\mathrm{Mg}$ & $\mathrm{Al}$ & $\mathrm{H}+\mathrm{Al}$ & SB & CTC & MO & V & EC \\
\hline & \multicolumn{2}{|c|}{$--\mathrm{mg} \mathrm{dm}^{-3}-$} & & $--\cdot$ & - & $-\mathrm{cm}$ & 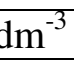 & 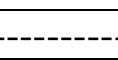 & 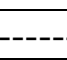 & - & --- & -- & $\mathrm{S} \mathrm{m}^{-1}$ \\
\hline$\sqrt{2}, 4$ & 47,4 & 1,6 & 0,4 & 6,8 & 4,5 & 1,5 & ALD & 3,1 & 6,5 & 9,6 & 3,5 & 67,1 & 0,22 \\
\hline
\end{tabular}

$\mathrm{pH}\left(\mathrm{CaCl}_{2}\right)$; Soma de bases (SB); Capacidade de troca de cátions (CTC); Matéria orgânica (MO); Saturação de Bases (V) e Condutividade elétrica (EC).

O espaçamento entre as plantas de alface foi de $0,25 \times 0,25 \mathrm{~m}\left(16\right.$ plantas por $\left.\mathrm{m}^{2}\right)$, num total de quatro linhas de plantas por canteiro. A irrigação foi realizada diariamente às $17 \mathrm{~h} 30$, sendo a lâmina determinada a partir da evapotranspiração de referência do dia anterior, obtida pela equação de Penman-Monteith, fornecida por uma estação climática automática instalada a $150 \mathrm{~m}$ do local do experimento. $\mathrm{O}$ volume total de água em cada um dos tratamentos, utilizando água residuária e água do depósito superficial, é apresentado na Tabela 3.

TABELA 3. Volume total de água aplicado em cada tratamento durante o ciclo da alface.

\begin{tabular}{lcccccc}
\hline Tratamentos & $\mathrm{Ar}$ & $\mathrm{GbR}$ & $\mathrm{GpR}$ & $\mathrm{Ad}$ & $\mathrm{GbD}$ & $\mathrm{GpD}$ \\
\hline Volume total (L) & $20.544,5$ & $4.841,4$ & $4.577,6$ & $20.614,5$ & $4.724,0$ & $4.603,1$ \\
\hline
\end{tabular}

Aspersão com água residuária (Ar); aspersão com água do depósito (Ad); gotejamento subterrâneo com água residuária $(\mathrm{GbR})$; gotejamento subterrâneo com água do depósito (GbD); gotejamento superficial com água residuária (GpR ), e gotejamento superficial com água do depósito (GpD).

A análise do teor de nutrientes da parte aérea da alface (Lactuca sativa L.), cv. Elisa, foi realizada no final do experimento, ou seja, 47 dias após o transplantio (DAT) das mudas em campo, compreendendo o período de 17-8 a 3-10-2001. Para essas análises, foram retiradas amostras de folhas recém-maduras de 12 plantas por unidade experimental, homogeneizadas em um saco plástico, totalizando três repetições por tratamento. Essas amostras foram inicialmente lavadas e secas em estufa de ar forçado a $60{ }^{\circ} \mathrm{C}$, até atingir peso constante. Em seguida, foram trituradas e passadas em peneira de $1,0 \mathrm{~mm}$, para posterior realização dos procedimentos de extração da solução. O tecido vegetal da parte aérea da alface foi analisado quanto à concentração de nitrogênio total, fósforo, potássio, cálcio, magnésio, enxofre, nitrato, ferro, manganês, cobre, zinco, sódio, boro, cobalto e molibdênio, por meio da técnica de espectrofotometria de absorção atômica e metodologia de preparo dos reagentes e 
soluções do material para a análise, conforme descrito em SILVA (1999). O procedimento utilizado

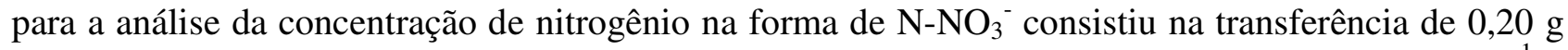
de amostra para um frasco de $50 \mathrm{~mL}$, onde se adicionaram $20 \mathrm{~mL}$ da solução de $\mathrm{H}_{2} \mathrm{SO}_{4} 0,05 \mathrm{~mol} \mathrm{~L}^{-1}+$ $\mathrm{K}_{2} \mathrm{SO}_{4} 0,05 \mathrm{~mol} \mathrm{~L}^{-1}$ e aquecido em banho-maria a $60^{\circ} \mathrm{C}$, por 10 minutos, agitando-se por duas horas e filtrados (MIYAZAWA et al.,1985). Após esse procedimento, uma porção da solução foi utilizada para a determinação da concentração de $\mathrm{N}_{-} \mathrm{NO}_{3}{ }^{-}$, por meio da cromatografia iônica com um cromatógrafo modelo DX-120 (Dionex Sunnyvale, CA) e calibrado para esse íon.

Os dados foram submetidos à análise de variância e comparação de média, aplicando-se o teste de Tukey, a 5\% e 1\% de probabilidade de erro, utilizando o Software STAT - Sistema de Análises Estatísticas, desenvolvido pela UNESP - Jaboticabal.

\section{RESULTADOS E DISCUSSÃO}

\section{Análise da água}

Observa-se, pela Tabela 1, que, na água residuária, os teores de nitrogênio $\left(\mathrm{N}^{-} \mathrm{NH}_{4}{ }^{+}\right)$foram em média de $35 \mathrm{mg} \mathrm{L}^{-1}$, enquanto na água do depósito não foi detectada sua presença. Os resultados da água residuária são considerados críticos para irrigação de hortaliças, conforme descrito por TRANI (2001). Para BRASIL (2005), na irrigação de hortaliças que são consumidas cruas, o limite do nitrogênio amoniacal para $\mathrm{pH} \leq 7,5$, situação deste trabalho, é de $3,5 \mathrm{mg} \mathrm{L}^{-1}$, portanto os resultados obtidos estão acima dos padrões recomendados por essa resolução. Os valores normais de $\mathrm{N}-\mathrm{NH}_{4}{ }^{+}$ em água de irrigação estão entre 0 e 5,0 $\mathrm{mg} \mathrm{L}^{-1}$ (AYERS \& WESTCOT, 1991), mas em águas residuais domésticas ou das fábricas processadoras de alimentos estão entre 10 e $50 \mathrm{mg} \mathrm{L}^{-1}$. Para a grande maioria das culturas, com exceção das hortaliças, não ocorrem efeitos prejudiciais com concentrações inferiores a $30 \mathrm{mg} \mathrm{L}^{-1}$.

O nitrogênio na forma de nitrato da água residuária apresentou o maior valor aos 25 DAT, sendo de $1,2 \mathrm{mg} \mathrm{L}^{-1}$. Segundo AYERS \& WESTCOT (1991), para valores de até $5 \mathrm{mg} \mathrm{L}^{-1}$ de nitrato, não existe restrição, e de 5 a $30 \mathrm{mg} \mathrm{L}^{-1}$ a restrição é ligeira a moderada. Já para TRANI (2001) e BRASIL (2005), os valores-limites de nitrato são de até $10,0 \mathrm{mg} \mathrm{L}^{-1}$ na água de irrigação para hortaliças, para que não ocorram problemas de contaminação de águas subterrâneas e superficiais e de saúde aos consumidores de alimentos com excesso de nitrato. Segundo BOINK \& SPEIJERS (2001), as hortaliças folhosas, dentre as quais a alface, o repolho e o espinafre, tendem a acumular nitrato em seus tecidos. A toxidez do nitrato em humanos, por si só, é baixa; no entanto, de 5 a $10 \%$ do $\mathrm{NO}_{3}{ }^{-}$ ingeridos na alimentação é convertido a nitrito $\left(\mathrm{NO}_{2}{ }^{-}\right)$na saliva bucal ou por redução gastrintestinal. Assim, o nitrito entrando na corrente sangüínea oxida o ferro $\left(\mathrm{Fe}^{2+} \rightarrow \mathrm{Fe}^{3+}\right)$ da hemoglobina, produzindo a metaemoglobina.

O nitrogênio facilmente assimilável pelas plantas está na forma de nitrato e amônio, sendo esse último somente encontrado em águas residuais ou aplicados pelos fertilizantes, que, em concentrações altas, podem ser benéficos durante as primeiras fases e prejudiciais durante a floração e frutificação das culturas, causando diminuição nos rendimentos, sendo uma medida útil a mistura ou mudança de água. No entanto, em plantas folhosas, como a alface, o repolho, etc., o nitrogênio é benéfico, devendo ser tomadas precauções somente quando ocorrer indícios de toxidez às plantas. Segundo KARAM et al. (2002), pode também ocorrer lixiviação do nitrato e causar problemas de contaminação de fontes de águas subterrâneas.

Os maiores teores de fósforo total na água residuária foram de $2,35 \mathrm{mg} \mathrm{L}^{-1}$, sendo inferiores aos verificados por MIRANDA (1995), que observou valor médio de $9,4 \mathrm{mg} \mathrm{L}^{-1}$ em efluente doméstico com tratamento secundário. Esses teores, de acordo com BRASIL (2005), estão acima do permitido para a Classe 1, indicada para a irrigação de hortaliças consumidas cruas, a qual permite um valor 
máximo de fósforo total de $0,025 \mathrm{mg} \mathrm{L}^{-1}$ (ambiente intermediário, com tempo de residência entre dois e 40 dias, e tributários diretos de ambiente lêntico). Os valores críticos de fósforo na água de irrigação, segundo TRANI (2001), são de $30 \mathrm{mg} \mathrm{L}^{-1}$, contudo observa-se grande disparidade entre as literaturas. Essas diferenças podem estar relacionadas aos objetivos do estudo desse parâmetro na água, sendo que, para a água de irrigação, o máximo de fósforo deve ser definido de forma que não ocorra a formação de precipitados como bicarbonato de cálcio. Nas fontes de água, como em rios e lagos, etc., o excesso de fósforo poderá favorecer o desenvolvimento de algas e causar a eutrofização. Outro aspecto importante do excesso de fósforo é que pode afetar o desenvolvimento da planta e interferir no equilíbrio nutricional da mesma e também há a possibilidade de causar danos à saúde humana.

Os valores de potássio na água residuária foram de, no máximo, 0,31 meq $\mathrm{L}^{-1}$, aos $47 \mathrm{DAT}$, não sendo suficiente para causar qualquer sintoma de toxidez na alface. O mesmo foi observado por MIRANDA (1995), em que a concentração média de potássio na água residuária foi de 0,64 meq $\mathrm{L}^{-1}$. Considerando o teor máximo de potássio, o total adicionado ao solo via água residuária foi da ordem de $24 \mathrm{~kg} \mathrm{ha}^{-1}$, estimando-se que cerca de 0,37 meq $\mathrm{L}^{-1}$ de $\mathrm{K}_{2} \mathrm{O}$ estavam presentes. Na água do depósito superficial, a concentração de potássio foi, no máximo, de $1,0 \mathrm{mg} \mathrm{L}^{-1}$, sendo esses valores normais para água de irrigação que, de acordo com AYERS \& WESTCOT (1991), estão entre 0 e 2,0 mg L $\mathrm{L}^{-1}$. O potássio adicionado ao solo pode não estar completamente disponível para as plantas, uma vez que, no solo, pode tomar diferentes formas (fixado, trocável ou constituinte da matéria orgânica). Para TRANI (2001), os valores máximos permissíveis de potássio na água de irrigação, para a aplicação em hortaliças folhosas, sem provocar perda de produtividade, estão entre 0,13 e 2,56 meq L $^{-1}$, mostrando, dessa forma, que a água utilizada não apresentou nenhuma restrição para uso na irrigação da alface.

O cálcio apresentou valores próximos de $1,5 \mathrm{meq} \mathrm{L}^{-1}$ nos tratamentos usando água residuária e, para o sódio, o valor máximo foi de $0,84 \mathrm{meq} \mathrm{L}^{-1}$, aos $25 \mathrm{DAT}$, e mínimo de $0,78 \mathrm{meq} \mathrm{L}^{-1}$, aos 10 DAT; valores bem abaixo do encontrado por MIRANDA (1995), que verificou concentração média de 2,96 meq $\mathrm{L}^{-1}$ para o sódio em água residuária com tratamento secundário. $\mathrm{O}$ valor máximo de sódio na água de irrigação deve estar entre 2,2 a 3,0 meq $\mathrm{L}^{-1}$, indicando que a água utilizada para a irrigação não apresentou indicação de que pudesse promover qualquer dano à cultura e ao solo. Danos severos somente ocorrem se os teores de sódio forem superiores ao valor citado, provocando absorção excessiva desse íon, especialmente se a umidade no solo for inferior a 30\% (CROOK, 1991 e TRANI, 2001). A concentração de magnésio variou entre 0,16 e $0,25 \mathrm{meq} \mathrm{L}^{-1}$. As concentrações normais para a irrigação, de acordo com AYERS \& WESTCOT (1991), são de 0-20 meq L $\mathrm{L}^{-1}$ para o cálcio, 0-5 meq $\mathrm{L}^{-1}$ para o magnésio e entre 0-40 meq $\mathrm{L}^{-1}$ para o sódio.

A razão de absorção de sódio máxima foi de $0,86\left(\mathrm{mmol}_{\mathrm{c}} \mathrm{L}^{-1}\right)^{1 / 2}$ (Tabela 1) na água residuária e de $0,21\left(\mathrm{mmol}_{\mathrm{c}} \mathrm{L}^{-1}\right)^{1 / 2}$ para a água do depósito. Segundo MELO (1978), com esses valores, não serão verificados efeitos negativos do sódio na irrigação, que só passam a provocar problemas às plantas com valores de RAS maiores que $10\left(\mathrm{mmol}_{\mathrm{c}} \mathrm{L}^{-1}\right)^{1 / 2}$. Dessa forma, observa-se que os valores de sódio e RAS da água residuária foram abaixo dos normalmente encontrados em água residuária, possivelmente devido ao sistema de tratamento do efluente (leitos cultivados com macrófitas), removendo significativa quantidade de nutrientes, como nitrogênio, fósforo, potássio, sódio, etc. Observa-se também que a água com predominância dos íons de sódio pode promover a dissolução das partículas de argila, diminuindo a permeabilidade do solo, causando redução da aeração do solo e inibição do desenvolvimento do sistema radicular das plantas e conseqüente perda de produção.

A condutividade elétrica da água residuária $\left(\mathrm{CE}_{\mathrm{a}}\right)$ foi de $0,52 \mathrm{dS} \mathrm{m} \mathrm{m}^{-1}$, aos 10 e $25 \mathrm{DAT}$, e de $0,63 \mathrm{dS} \mathrm{m}^{-1}$, aos $47 \mathrm{DAT}$. Considerando a classificação para a irrigação proposta por AYERS \& WESTCOT (1991), a água utilizada possuía salinidade sem nenhum grau de restrição, em que $\mathrm{CE}_{\mathrm{a}}$ pode chegar a até $0,7 \mathrm{dS} \mathrm{m} \mathrm{m}^{-1}$, podendo ser utilizada na irrigação sem nenhum problema, até mesmo para culturas mais sensíveis à salinidade. Segundo a EPAV (1991), a CE da água residuária 
caracteriza-se como de Classe $2\left(0,3\right.$ a $\left.0,8 \mathrm{dS} \mathrm{m}^{-1}\right)$. Assim, a aplicação dessa água por aspersão, com concentração próxima do limite superior, pode provocar leves queimaduras das folhas em culturas mais sensíveis aos sais, principalmente em altas temperaturas durante o dia e com baixas taxas de aplicação.

O valor médio de $\mathrm{pH}$ na água residuária foi de 7,3 e, na do depósito, de 7,0; valores esses dentro do intervalo recomendado por BRASIL (2005) para irrigação de hortaliças, que devem estar entre 6,0 e 9,0 .

Os maiores valores de enxofre foram de $3,2 \mathrm{mg} \mathrm{L}^{-1}$ e $1,5 \mathrm{mg} \mathrm{L}^{-1}$ para a água residuária e água do depósito, respectivamente. Normalmente, o enxofre provém da utilização do sulfato de amônio como fonte de nitrogênio nas aplicações complementares, já que possui enxofre em sua formulação, porém, em água residuária, o enxofre apresenta valores elevados, contudo, normalmente, não ocasiona qualquer tipo de problema às plantas.

Os teores de $\mathrm{DBO}_{5}$ observados em praticamente todos os tratamentos e datas de amostragem foram acima do máximo permitido para a Classe 1 , que a $20{ }^{\circ} \mathrm{C}$ é de até $3 \mathrm{mg} \mathrm{L}^{-1}$ (BRASIL, 2005). No entanto, observa-se grande variação da $\mathrm{DBO}_{5}$ entre as datas de amostragem, a qual é devida à qualidade do efluente tratado, que apresenta variações em função da intensidade de uso das dependências da universidade, tanto durante os dias da semana, como durante o período do dia, além de possíveis variações de vazão de entrada no sistema de tratamento do efluente e das condições climáticas no período de coleta das amostras de água.

O teor de boro máximo, considerando a água residuária e a do depósito, foi de $0,3 \mathrm{mg} \mathrm{L}^{-1}$, não apresentando nenhuma restrição para aplicação na irrigação que, de acordo com AYERS \& WESTCOT (1991), poderá haver problema, quando a concentração atingir pelo menos $0,7 \mathrm{mg} \mathrm{L}^{-1}$, enquanto, para TRANI (2001), os valores-limite para a água de irrigação estão entre 0,5 e $1,0 \mathrm{mg} \mathrm{L}^{-1}$. O limite máximo para BRASIL (2005), na água de irrigação da Classe 1 , é de $0,5 \mathrm{mg} \mathrm{L}^{-1}$. Os limites recomendados de boro em águas residuárias utilizadas na irrigação, em curto prazo, podem ser de até $2 \mathrm{mg} \mathrm{L}^{-1}$ (CROOK, 1991). A alta concentração de boro pode ser encontrada em efluente doméstico, normalmente entre 0,5 e $1,0 \mathrm{mg} \mathrm{L}^{-1}$, sendo atribuído ao uso de componentes à base de boro, em produtos de limpeza (KIRKHAM, 1986).

$\mathrm{Na}$ água residuária, a concentração de ferro não ultrapassou $1,1 \mathrm{mg} \mathrm{L}^{-1}$ e na água do depósito $0,9 \mathrm{mg} \mathrm{L}^{-1}$. De acordo com TRANI \& CARRIJO (2004), os valores máximos de ferro na água de irrigação devem estar entre 0,2 e $1,5 \mathrm{mg} \mathrm{L}^{-1}$; acima desse limite superior, pode ocorrer precipitação de $\mathrm{F}_{2} \mathrm{Cl}_{3}$ em águas com altos teores de cloro. Os valores menores de ferro total devem ser utilizados em culturas que são consumidas cruas, como indicação de BRASIL (2005), que recomenda o limite máximo de $0,3 \mathrm{mg} \mathrm{L}^{-1}$.

\section{Análise da parte aérea da planta}

Os teores de macronutrientes e micronutrientes na parte aérea da alface aos 47 DAT e a comparação de médias, para os todos os tratamentos, estão apresentados na Tabela 4.

De acordo com a análise de variância, não houve efeito significativo do nitrogênio entre os tratamentos. Isso significa que o maior valor de $\mathrm{N}$ na água residuária não influenciou na absorção e no acúmulo de nitrogênio na parte aérea da alface, com valores muito próximos aos obtidos na água superficial. O tipo de sistema de irrigação utilizado também não ocasionou diferença significativa entre os tratamentos. A ausência de diferença significativa pode ser devida ao fato de o $\mathrm{N}$ presente no solo ter sido o suficiente para suprir as necessidades da planta, o que pode ter sido influenciado pela aplicação de sulfato de amônio em cobertura, três vezes durante o ciclo, em todos os tratamentos. 
TABELA 4. Teores médios dos nutrientes na parte aérea da alface aos 47 dias após o transplantio e comparação de médias pelo teste de Tukey, a 5\% de significância.

\begin{tabular}{|c|c|c|c|c|c|c|c|c|}
\hline \multirow{3}{*}{ Parâmetros } & \multicolumn{6}{|c|}{ Tratamentos } & \multirow{2}{*}{$\begin{array}{l}\text { Desvio- } \\
\text { Padrão }\end{array}$} & \multirow{2}{*}{$\begin{array}{l}\text { Coeficiente } \\
\text { de Variação }\end{array}$} \\
\hline & $\mathrm{Ar}$ & GbR & GpR & $\mathrm{Ad}$ & GbD & GpD & & \\
\hline & \multicolumn{6}{|c|}{---------------------------------------------g kg } & \multicolumn{2}{|c|}{---------- \% ---------. } \\
\hline J & $31,6 \mathrm{Aa}$ & $33,4 \mathrm{Aa}$ & $35,7 \mathrm{Aa}$ & $31,8 \mathrm{Aa}$ & $33,8 \mathrm{Aa}$ & $31,3 \mathrm{Aa}$ & 2,73 & 8,24 \\
\hline K & $7 \mathrm{Aa}$ & 50 & $52,3 \mathrm{Aa}$ & $54,3 \mathrm{Aa}$ & $52,7 \mathrm{Aa}$ & $50,9 \mathrm{Aa}$ & & \\
\hline $\mathrm{a}$ & $12,2 \mathrm{Aa}$ & 13,1 Aa & $13,2 \mathrm{Aa}$ & $11,9 \mathrm{Aa}$ & $11,4 \mathrm{Aa}$ & $11,8 \mathrm{Aa}$ & 3 & 7,68 \\
\hline & $7 \mathrm{Aa}$ & 4,8 Aa & 4,1 Aa & 4,5 Aa & $4,6 \mathrm{Aa}$ & 5,0 Aa & 0,51 & 11,05 \\
\hline $\lg$ & $3,0 \mathrm{Aa}$ & $3,5 \mathrm{Aa}$ & $3,0 \mathrm{Aa}$ & $2,5 \mathrm{Aa}$ & $3,0 \mathrm{Aa}$ & $3,2 \mathrm{Aa}$ & 0,32 & 10,62 \\
\hline & 3,7 Aa & 3,7 Aa & 4,3 Aa & 4,2 Aa & $4,6 \mathrm{Aa}$ & 4,2 Aa & 0,39 & 9,43 \\
\hline \multicolumn{7}{|c|}{ Parâmetros ----------------------------------- $\mathrm{mg} \mathrm{kg}^{-1}$} & \multicolumn{2}{|c|}{--------- \% ---------- } \\
\hline $\mathrm{Mn}$ & $104,7 \mathrm{Aa}$ & $62,3 \mathrm{Aa}$ & $61,7 \mathrm{Aa}$ & $72,3 \mathrm{Aa}$ & $88,3 \mathrm{Aa}$ & $61,7 \mathrm{Aa}$ & 18,93 & 25,19 \\
\hline 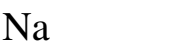 & $985 \mathrm{Aa}$ & $676 \mathrm{Ab}$ & $617 \mathrm{Ab}$ & $107 \mathrm{Ba}$ & $111 \mathrm{Ba}$ & $113 \mathrm{Ba}$ & 107,86 & 24,81 \\
\hline & $325 \mathrm{Aa}$ & $287 \mathrm{Aa}$ & $257 \mathrm{Aa}$ & $155 \mathrm{Bb}$ & $362 \mathrm{Aa}$ & $297 \mathrm{Aab}$ & 86,83 & 31 \\
\hline $\mathrm{u}$ & $0 \mathrm{Aa}$ & $19,0 \mathrm{Aa}$ & $18,0 \mathrm{Aa}$ & $14,7 \mathrm{Aa}$ & $16,3 \mathrm{Aa}$ & $15,7 \mathrm{Aa}$ & 34 & 10 \\
\hline 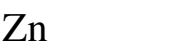 & $50,0 \mathrm{Aa}$ & 55,3 Aa & 46,7 Aa & $44,7 \mathrm{Aa}$ & $48,7 \mathrm{Aa}$ & $45,0 \mathrm{Aa}$ & 14,81 & 28,65 \\
\hline B & $38,3 \mathrm{Aa}$ & 35,7 Aa & $33,7 \mathrm{Aa}$ & $35,6 \mathrm{Aa}$ & $33,5 \mathrm{Aa}$ & $32,4 \mathrm{Aa}$ & 3,73 & 10,67 \\
\hline 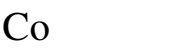 & $1,7 \mathrm{Aa}$ & 1,3 Aa & $1,7 \mathrm{Aa}$ & $2,0 \mathrm{Aa}$ & $2,0 \mathrm{Aa}$ & 2,0 Aa & 0,43 & 24,45 \\
\hline Мо & $2,7 \mathrm{Aa}$ & 3,3 Aa & 2,7 Aa & $3,0 \mathrm{~A}$ & $4,0 \mathrm{Aa}$ & 4,3 Aa & 0,61 & 18,17 \\
\hline $\mathrm{N}-\mathrm{NO}_{3}^{-}$ & $1.090 \mathrm{Aa}$ & $1.053 \mathrm{Aa}$ & $1.382 \mathrm{Aa}$ & $251 \mathrm{Aa}$ & $515 \mathrm{Aa}$ & $352 \mathrm{Aa}$ & 204,6 & 26,4 \\
\hline
\end{tabular}

Média de três amostras, cada uma composta por folhas de 12 plantas.

A primeira letra na linha compara um mesmo tipo de irrigação entre os diferentes tipos de água.

A segunda letra na linha compara o mesmo tipo de água entre os diferentes tipos de irrigação.

Aspersão com água residuária (Ar), aspersão com água do depósito (Ad), gotejamento subterrâneo com água residuária $(\mathrm{GbR})$, gotejamento subterrâneo com água do depósito $(\mathrm{GbD})$, gotejamento superficial com água residuária $(\mathrm{GpR}) \mathrm{e}$ gotejamento superficial com água do depósito $(\mathrm{GpD})$.

Os teores médios obtidos de nitrogênio total na parte aérea da alface foram de 31,6; 33,4 e $35,7 \mathrm{~g} \mathrm{~kg}^{-1}$ para os tratamentos Ar, GbR e GpR, e de 31,8; 33,8 e 31,3 $\mathrm{g} \mathrm{kg}^{-1}$ para os tratamentos Ad, $\mathrm{GbD}$ e $\mathrm{GpD}$, respectivamente. Esses valores são considerados adequados para a alface, situando-se próximo ao limite inferior, que é de 30 a $50 \mathrm{~g} \mathrm{~kg}^{-1}$ (TRANI \& RAIJ, 1997). ALVARENGA et al. (2003) observaram em alface americana que tanto Ca quanto $\mathrm{N}$ tiveram influência significativa na absorção e no acúmulo de nitrogênio na parte aérea da alface com $33,4 \mathrm{~g} \mathrm{~kg}^{-1}$, aos 56 dias após o transplantio, enquanto GARCIA (1982) observou teor de 469,6 mg por planta.

O fósforo, em todos os tratamentos, apresentou níveis adequados para a alface, conforme descrito por TRANI \& RAIJ (1997). A concentração foi próxima ao limite inferior do intervalo mencionado por esses autores, que é de 4,0 a 7,0 $\mathrm{g} \mathrm{kg}^{-1}$. Mesmo havendo teores mais elevados de fósforo na água residuária que na água do depósito superficial, assim como ocorreu para o nitrogênio, potássio e cálcio, não houve efeito significativo desse íon na parte aérea da alface. $\mathrm{O}$ tratamento $\mathrm{GpD}$ foi o que apresentou maior teor médio de fósforo $\left(5,0 \mathrm{~g} \mathrm{~kg}^{-1}\right)$, seguido pelo $\mathrm{GpR}\left(4,8 \mathrm{~g} \mathrm{~kg}^{-1}\right)$. Embora na água residuária houvesse mais fósforo na água do depósito, esses valores são considerados baixos, se observados os índices normalmente encontrados em efluente. Isso se deve ao tipo de tratamento dado ao efluente, ou seja, leito cultivado, onde partes desse nutriente foram removidas pelas plantas para sua formação celular, sendo dependente da fase de crescimento das macrófitas como comprovado por VALENTIM (2003), que observou também que, para a macrófita Typha sp., o valor médio de redução de fósforo ficou em torno de 0,8 e para a Eleocharis sp. 0,95, o que é desfavorável quando se tem como objetivo o reúso de água residuária como fonte de nutriente para as plantas. Outro fator que pode ter influenciado na não-diferenciação entre os tratamentos foi a presença de fósforo no solo em 
quantidade suficiente para atendimento da necessidade da alface, uma vez que foi realizada a aplicação de fósforo com adubação mineral no preparo do solo.

O potássio apresentou teor adequado na parte aérea da planta em todos os tratamentos, não havendo diferença significativa entre os tratamentos, mesmo havendo maior concentração desse íon na água residuária em relação à do depósito superficial. As mesmas observações realizadas para o fósforo quanto ao sistema de tratamento podem ser aplicadas para justificar a não-diferenciação do potássio na parte aérea. Os teores obtidos nos tratamentos Ar, GbR e GpR foram de 49,7; 50,1 e 52,3 $\mathrm{g} \mathrm{kg}^{-1}$, enquanto nos tratamentos $\mathrm{Ad}, \mathrm{GbD}$ e $\mathrm{GpD}$ foram de 54,$3 ; 52,7$ e $50,9 \mathrm{~g} \mathrm{~kg}^{-1}$, respectivamente, sendo esses teores maiores aos observados por ALVARENGA et al. (2003) em alface americana, os quais obtiveram valores entre 25,0 e 27,0 $\mathrm{g} \mathrm{kg}^{-1}$ aos 56 DAT, podendo ser devido à extração do potássio do solo pela planta, geralmente presente em níveis altos no solo, como o do local de estudo.

Considerando a análise de variância, não houve efeito significativo entre os tratamentos para o cálcio. No entanto, considerando os valores absolutos, observa-se que os teores de cálcio foram maiores nos tratamentos Ar, GbR e GpR com teores de 12,2;13,1 e 13,2 $\mathrm{g} \mathrm{kg}^{-1}$, comparados aos tratamentos $\mathrm{Ad}, \mathrm{GbD}$ e $\mathrm{GpD}$ que foram de 11,$9 ; 11,4 \mathrm{e} 11,8 \mathrm{~g} \mathrm{~kg}^{-1}$, respectivamente. Isso se deve à presença de cálcio na água residuária que, conseqüentemente, ficou retido no solo, influenciando no acúmulo desse íon na planta. Em todos os tratamentos, os níveis foram adequados para plantas bem nutridas, que, de acordo com TRANI \& RAIJ (1997), são normalmente até $15 \mathrm{~g} \mathrm{~kg}^{-1}$. É provável que as quantidades de cálcio existentes no solo $\left(4,5 \mathrm{cmol} \mathrm{dm}^{-3}\right)$ tenham sido suficientes para suprir a necessidade planta, embora a água residuária tenha favorecido a elevação do cálcio na parte aérea da alface. ALVARENGA et al. (2003) constataram que a aplicação de cálcio via foliar não teve influência significativa no teor e acúmulo dos macronutrientes na parte aérea da planta, inclusive do próprio cálcio, sendo considerada desnecessária, observando teor de cálcio de $15,1 \mathrm{~g} \mathrm{~kg}^{-1}$ na alface americana.

$\mathrm{O}$ teor de magnésio obtido foi menor que o adequado para a alface, sendo de $2,5 \mathrm{~g} \mathrm{~kg}^{-1}$ no tratamento Ar e $3,5 \mathrm{~g} \mathrm{~kg}^{-1}$ no tratamento GbR, conforme apresentado por TRANI \& RAIJ (1997), que recomendam estar entre 4,0 e $6,0 \mathrm{~g} \mathrm{~kg}^{-1}$, possivelmente devido à baixa concentração desse íon na água de irrigação. O magnésio já existente no solo, assim como a relação cálcio/magnésio, não foi suficiente para atender à necessidade da planta e, conseqüentemente, manter a concentração considerada adequada de magnésio. Plantas de alface bem nutridas devem apresentar cerca de $3,5 \mathrm{~g} \mathrm{~kg}^{-1} \mathrm{de} \mathrm{Mg}$.

Ao contrário do que ocorreu com os demais parâmetros, que apresentavam níveis adequados para a alface, com exceção do magnésio, os teores de enxofre, em todos os tratamentos, apresentaram valores acima dos adequados para a alface, que deverá estar entre 1,5 e $2,5 \mathrm{~g} \mathrm{~kg}^{-1}$. No entanto, neste experimento, o maior teor foi $4,6 \mathrm{~g} \mathrm{~kg}^{-1}$ no tratamento GbD e o menor foi de $3,7 \mathrm{~g} \mathrm{~kg}^{-1}$, nos tratamentos Ar e GbR, superiores aos observados por ALVARENGA et al. (2003), que obtiveram teores de $2,7 \mathrm{~g} \mathrm{~kg}^{-1}$. Esses teores mostram que, embora a água residuária tenha apresentado maior concentração de enxofre, não resultou em acúmulo significativo nas folhas das plantas nesses tratamentos, que pode ter sido motivado pela utilização do sulfato de amônio nas aplicações suplementares de nitrogênio, uma vez que possui $24 \%$ de enxofre em sua formulação.

O sódio foi o micronutriente que apresentou a maior elevação na parte aérea da alface, e nos tratamento Ar, GbR e GpR foram 9,0; 6,0 e 5,5 vezes maiores que os tratamentos $\mathrm{Ad}, \mathrm{GbD}$ e $\mathrm{GpD}$, respectivamente (Tabela 4). Esse comportamento é inerente às plantas de alface, que têm grande capacidade de reter esse íon nos seus tecidos. Os teores foram de $985 ; 676 ; 617 ; 107 ; 111 \mathrm{e}$ $113 \mathrm{mg} \mathrm{kg}^{-1}$, respectivamente, para os tratamentos Ar, GbR, GpR, Ad, GbD e GpD. O alto teor de sódio observado esteve associado a sua concentração na água residuária, provavelmente o maior responsável em todos os tipos de irrigação, devido a sua disponibilidade no solo, decorrente da aplicação da água residuária. Observou-se que houve diferença significativa, a $1 \%$ de probabilidade, entre os tratamentos com água residuária e do depósito superficial nos três sistemas de irrigação. 
Constatou-se, também, que a aspersão diferiu do gotejamento subterrâneo e superficial utilizando água residuária quanto aos teores de sódio.

A exemplo do que ocorreu com os teores de ferro, manganês e zinco, o sódio apresentou teores mais elevados quando a água residuária foi aplicada por aspersão, levando à hipótese de que essa água aplicada sobre as folhas pode ter facilitado a absorção de parte de alguns nutrientes, embora a maior parte dos nutrientes e da água aplicada pela aspersão escoa pelas folhas, atingindo o solo, onde são absorvidos pelas raízes das plantas.

Os teores de cobre foram de 17,0; 19,0 e 18,0 mg kg-1 para os tratamentos Ar, GbR e GpR, enquanto para os tratamentos $\mathrm{Ad}, \mathrm{GbD}$ e GpD foram de 14,7; 16,3 e 15,7 $\mathrm{mg} \mathrm{kg}^{-1}$, respectivamente. Comparando os resultados obtidos com outros autores, verificou-se que, de acordo com SANCHES et al. (1991) e ADAMS et al. (1979), a concentração obtida foi acima dos níveis adequados para TRANI \& RAIJ (1997) e JONES Jr. et al. (1991). As variações observadas entre os autores podem ser explicadas pelas diferentes cultivares, condições de clima, solo e disponibilidade de nutrientes na água de irrigação e solo, disponibilizando ou interferindo negativamente na absorção dos nutrientes pelas plantas.

Observou-se que os teores de boro foram de 39,3; 35,7 e 33,7 $\mathrm{mg} \mathrm{kg}^{-1}$, respectivamente, para os tratamentos Ar, GbR e GpR, enquanto para a Ad, GbD e GpD foram de 36,6; 33,5 e 32,4 mg kg ${ }^{-1}$, não apresentando diferença significativa entre os tratamentos. Os teores de boro, conforme TRANI \& RAIJ (1997) e SANCHES et al. (1991), nas folhas de alface, são bastante amplos, variando entre 20 e $60 \mathrm{mg} \mathrm{kg}^{-1}$. Essa ampla faixa descrita pelos autores, a exemplo do cobre, deve-se basicamente aos mesmos fatores, especialmente a água, que pode conter altas concentrações de boro quando houver contribuição de efluentes com presença de material de limpeza, o que não foi o caso deste trabalho, uma vez que, em praticamente todas as análises, os valores de boro foram abaixo do limite de detecção do aparelho utilizado na análise $\left(0,1 \mathrm{mg} \mathrm{L}^{-1}\right)$.

Os teores de ferro foram de 325; 287 e $257 \mathrm{mg} \mathrm{kg}^{-1}$, respectivamente, para os tratamentos Ar, GbR e GpR, enquanto para os tratamentos Ad, GbD e GpD foram de 155; 362 e $297 \mathrm{mg} \mathrm{kg}^{-1}$ (Tabela 3), apresentando diferença significativa a 5\% de probabilidade, entre os tratamentos Ar e Ad. Também houve diferença significativa do ferro presente na alface do tratamento Ad em relação aos tratamentos $\mathrm{GbD}$ e GpD, sendo uma possível hipótese, a diferença de concentração desse micronutriente no solo, ou também pode estar relacionada à quantidade desse íon na água de irrigação, estando presente em menor concentração no tratamento Ad. Os resultados obtidos para o tratamento Ad encontram-se na faixa adequada para alface, segundo SANCHES et al. (1991), porém acima das recomendações de outros autores como TRANI \& RAIJ (1997), JONES Jr. et al. (1991) e ADAMS et al. (1979).

O teor de manganês apresentou níveis adequados para plantas bem nutridas, indicando que o solo contém esse micronutriente em quantidade suficiente para atender à necessidade da cultura. A absorção de manganês é prejudicada pela alta concentração de potássio, cálcio, magnésio, cobre, zinco e sódio. SANCHES et al. (1991), TRANI \& RAIJ (1997) e JONES JR. et al. (1991) definem uma faixa ampla, variando entre 15 e $250 \mathrm{mg} \mathrm{kg}^{-1}$ como adequada para a parte aérea da alface. Observou-se que os níveis de manganês apresentaram variações entre os tratamentos, sendo que o máximo obtido foi no

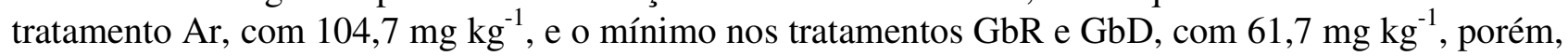
de acordo com a análise de variância, não houve diferença significativa entre os tratamentos.

Os teores de zinco encontrados podem ser considerados adequados para a alface, variando entre 44,7 e 55,3 $\mathrm{mg} \mathrm{kg}^{-1}$, que, de acordo com TRANI \& RAIJ (1997), os índices adequados variam entre 25 e $250 \mathrm{mg} \mathrm{kg}^{-1}$. O zinco é um micronutriente que, quando em altas concentrações no solo, provoca sintomas de toxidez em algumas culturas, sendo reduzidos esses efeitos em solos com $\mathrm{pH}$ acima de 6,0 e em solos com textura arenosa e elevado teor de matéria orgânica. A exemplo do cobre, manganês, 
cobalto e molibdênio, o zinco não foi analisado na água de irrigação, portanto não é possível fazer inferências sobre a contribuição desses íons presentes na água sobre o teor desses na parte aérea da planta. No entanto, são encontrados, geralmente no solo, em quantidade suficiente para atender à demanda das plantas.

O cobalto não é um nutriente essencial para a alface, sendo considerado "útil" às leguminosas por favorecerem, de maneira indireta, a fixação de $\mathrm{N}$ pelas plantas. Não houve diferença significativa entre os tratamentos, em que os teores de cobalto foram de $2,0 \mathrm{mg} \mathrm{kg}^{-1}$ nos tratamentos Ad, GbD e GpD, 1,7 mg kg ${ }^{-1}$ nos tratamentos Ar e GbR e 1,3 $\mathrm{mg} \mathrm{kg}^{-1}$ no GpR.

Não houve diferença significativa entre os tratamentos para o molibdênio. Esse nutriente é pouco discutido na literatura, porém alguns autores, como TRANI \& RAIJ (1997), citam como nível adequado para a alface a faixa de 0,8 a $1,4 \mathrm{mg} \mathrm{kg}^{-1}$. Observou-se que, com exceção do tratamento $\mathrm{GbR}$, os demais mostraram teores mais elevados aos definidos por esses autores, devendo-se possivelmente à presença desse elemento no solo em quantidades maiores que o necessário para a alface. A toxidez do molibdênio e seu grau de dano estão relacionados à quantidade ingerida em relação ao cobre e ao $\mathrm{SO}_{4}{ }^{-}$. Altas concentrações de molibdênio com baixas concentrações de cobre ingeridas constituem-se na pior situação possível. Dessa forma, o risco associado à acumulação nos tecidos vegetais deve ser cuidadosamente avaliado, antes da irrigação de culturas, mesmo as que serão utilizadas para alimentação animal (EPAV, 1991).

As concentrações médias de nitrato na parte aérea da alface variaram consideravelmente entre os tratamentos, sendo de 1.090; 1.053 e $1.382 \mathrm{mg} \mathrm{kg}^{-1}$, respectivamente, para os tratamentos Ar, GbR e GpR. Valores semelhantes foram obtidos por KIRKHAM (1986), com alface, utilizando água residuária municipal, verificando que o nitrato não provocou nenhum dano às plantas, ao contrário, foi benéfico para o desenvolvimento das mesmas. Para os tratamentos Ad, GbD e GpD, os valores médios foram de 251; 516 e $352 \mathrm{mg} \mathrm{kg}^{-1}$, respectivamente, inferiores, portanto, aos obtidos nos tratamentos utilizando água residuária. A variação entre os tratamentos, possivelmente, foi devida à concentração desse nutriente na água de irrigação, havendo maior acúmulo desse nutriente com sistema de irrigação por gotejamento do que na aspersão. O sistema de cultivo também é um fator determinante no teor de nitrato em folhas da alface, conforme relatam MIYAZAWA et al. (2001), mostrando que o teor de $\mathrm{N}_{-} \mathrm{NO}_{3}{ }^{-}$na alface cultivada em sistema orgânico variou entre 250 e $6.570 \mathrm{mg} \mathrm{kg}^{-1}$, e metade das amostras de alface apresentou concentração menor que $1.000 \mathrm{mg} \mathrm{kg}^{-1}$ e $2 / 3 \mathrm{com}$ teor inferior a $500 \mathrm{mg} \mathrm{kg}^{-1}$.

MANTOVANI et al. (2005) relatam que o teor de nitrato é um importante índice da qualidade dos alimentos, mas existem problemas na sua determinação. Dessa forma, compararam os procedimentos da coluna redutora contendo cádmio, da destilação, do ácido salicílico e da mistura redutora contendo zinco, na quantificação de nitrato em tecido vegetal da alface, observando que os procedimentos da coluna redutora contendo cádmio e o da destilação são os mais adequados na quantificação de nitrato em tecido vegetal, observando os seguintes valores: $1.293 ; 2.259 ; 1.077$ e $1.137 \mathrm{mg} \mathrm{kg}^{-1}$, respectivamente.

De acordo com a definição da FAO, o Índice de Máxima Ingestão Diária Admissível (IDA) de nitrato e nitrito são de $5 \mathrm{mg} \mathrm{kg}^{-1}$ e $0,2 \mathrm{mg} \mathrm{kg}^{-1}$ de peso corporal, respectivamente, e que uma pessoa de $70 \mathrm{~kg}$ poderá consumir até $350 \mathrm{mg}$ de nitrato por dia. Na União Européia, o máximo permitido de nitrato em alface é de 3.500 a $4.500 \mathrm{mg} \mathrm{kg}^{-1}$ de peso fresco (BOINK \& SPEIJERS, 2001). Observa-se que, mesmo as plantas do sistema de irrigação com água residuária poderão ser consumidas sem perigo de causar danos à saúde, sendo necessário o consumo correspondente a aproximadamente $0,5 \mathrm{~kg}$ por dia para atingir o valor do IDA. 


\section{CONCLUSÕES}

O teor do nitrogênio total, fósforo, potássio, cálcio, nitrato, ferro, manganês, cobre, zinco, boro, cobalto e molibdênio para todos os tratamentos foi considerado normal e adequado para plantas bem nutridas; já o magnésio foi menor, não sendo influenciado pelo tipo de água, enquanto o enxofre e o sódio foram maiores, porém, em nenhum dos tratamentos, houve sintoma de toxidez ou deficiência de nutrientes às plantas. A utilização dos sistemas de irrigação por aspersão, gotejamento subterrâneo e gotejamento superficial para aplicação de água residuária tratada com leitos cultivados com macrófitas não interferiu no teor de nutrientes na parte aérea da alface.

\section{AGRADECIMENTO}

À Fundação de Amparo à Pesquisa do Estado de São Paulo, pelo auxílio concedido e à Faculdade de Engenharia Agrícola da UNICAMP.

\section{REFERÊNCIAS}

ADAMS, P.; GRAVES, C.J.; WINDSON, G.W. Effects of copper deficiency and liming on the yield, quality and copper status of tomatoes, lettuce, and cucumber grown in peat. Scientia Horticultural, Amsterdam, v.9, n.3, p.199-205, 1979.

ALVARENGA, M.A.R.; SILVA, E.C. da; SOUZA, R.J. ; CARVALHO, J.G. Teores e acúmulo de macronutrientes em alface americana, em função da aplicação de nitrogênio no solo e de cálcio via foliar. Ciência Agrotécnica, Lavras, v.27, p.1569-75, dez., 2003. Edição Especial.

APHA/AWWA/WPCF. Standard methods for examination of water and wastewater. $19^{\text {th }} \mathrm{ed}$. Washington: American Public Heath Association, 1995.

AYERS, R.S.; WESTCOT, D.W. A qualidade da água na agricultura. Campina Grande: UFPB, 1991. 218 p. (Estudos da FAO: Irrigação e Drenagem, 29, Revisado 1).

BOINK, A.; SPEIJERS, G. Health effect of nitrates and nitrites, a review. Acta Horticultura, Cairo, n.563, p.29-36, 2001.

BOUWER, H. Agricultural and municipal use of wastewater. Water Science Technology, Oxford, v.26, n.7-8, p.1583-91, 1992.

BRASIL. Resolução CONAMA. Conselho Nacional do Meio Ambiente $\mathrm{n}^{\circ} .357$ de 17 de março de 2005. Diário Oficial da República Federativa do Brasil, Brasília, DF, 2005. 23 p.

CROOK, J. Quality criteria for reclaimed water. Water Science Technology, Oxford, v.24, n.9, p.10921, 1991.

ENVIRONMENT PROTECTION AUTHORITY OF VICTORIA - EPVA. Guidelines for wastewater irrigation, Melbourne, 1991. 60 p. (Publication, 168).

FAQUIN, V. Nutrição mineral e diagnose do estado nutricional de hortaliças. Lavras: Universidade Federal de Lavras, FAEPE, 2004. 88 p.

FASCIOLO, G.E.; MECA, M.I.; GABRIEL, E.; MORÁBITO, J. Effects on crops of irrigation with treated municipal wastewaters. Water Science and Technology, Oxford, v.45, n.1, p.133-8, 2002.

GARCIA, L.L.C. Absorção de macro e micronutrientes e sintomas de carência de macronutrientes em alface (Lactuca sativa L.), Cv. Brasil 48 e clause's aurelia. 1982. 78 f. Dissertação (Mestrado em Solos e Nutrição de Plantas) - Escola Superior de Agricultura "Luiz de Queiroz", Universidade de São Paulo, Piracicaba, 1982.

HACH Company. DBOTrak instrument manual. $3^{\text {th }}$ ed. Loveland, 1997. 64 p. 
JONES JR., J.B.; WOLF, B.; MILLS, H.A. Plant analysis handbook. Athens: MicroMacro Publ., 1991. 213 p. Appendix 1. Table of interpretative values: vegetables, 1991. p.177-187.

KARAM ,F.; MOUNZER, O.; SARKIS, F.; LAHOUD, R. Yield and nitrogen recovery of lettuce under different irrigation regimes. Journal Applied Horticulture, Indiranagar, v.4, n.2, p.70-6, 2002.

KIRKHAM, M.B. Problems of using wastewater on vegetable crops. HortScience, Alexandria, v.21, n.1, p.24-7, 1986.

LISBÃO, R.S.; NAGAI, H.; TRANI, P.E. Alface. Boletim Técnico do Instituto Agronômico, Campinas, n.200, p.11-12, 1990.

MANTOVANI, J.R.; CRUZ, M.C.P.; FERREIRA, M.E.; BARBOSA, J.C. Comparação de procedimentos de quantificação de nitrato em tecido vegetal. Pesquisa Agropecuária Brasileira, Brasília, v.40, n.1, p.53-9, jan. 2005.

MELO, J.A.S. Aplicação de águas residuárias no solo como método de tratamento, disposição final e reciclagem de águas usadas. Engenharia Sanitária, Rio de Janeiro, v.17, n.1, p.82-91, jan./mar., 1978.

MIRANDA, T.L.G. Reúso de efluente de esgoto doméstico na irrigação de alface (Lactuca sativa L.). 109 f. 1995. Dissertação (Mestrado em Engenharia de Recursos Hídricos e Saneamento Ambiental) Instituto de Pesquisas Hidráulicas, Universidade Federal do Rio Grande do Sul, Porto Alegre, 1995.

MIYAZAWA, M.; PAVAN, M.A.; BLOCH, M.F.M. Determinação espectrofotométrica de nitrato em extrato de solos sem redução química. Pesquisa Agropecuária Brasileira, Brasília, v.20, n.1, p.129-33, 1985.

MIYAZAWA, M.; KHATOUNIAN, C.A; ODENATH-PENHA, L.A. Teor de nitrato nas folhas de alface produzidas em cultivo convencional, orgânico e hidropônico. Agroecologia Hoje, Botucatu, Ano II, v.7, p.23, fev./mar., 2001.

SANCHEZ, C.A.; SNYDER, G.H.; BURDINE, H.W. DRIS evaluation of nutricional status of crisphead lettuce. HortScience, Alexandria, n.26, n.3, p.274-6, 1991.

SANDRI, D. Irrigação da cultura da alface com água residuária tratada com leitos cultivados com macrófita. 186 f. Tese (Doutorado em Engenharia de Água e Solo) - Faculdade de Engenharia Agrícola, Universidade Estadual de Campinas, Campinas, 2003.

SILVA, F.B. Manual de análises químicas de solos, plantas e fertilizante. Brasília: EMBRAPA Comunicação para Transferência de Tecnologia, 1999. 370 p.

TRANI, P.E.; RAIJ, B. van. Hortaliças. Boletim Técnico do Instituto Agronômico, Campinas, n. 100, p.30-6, 1997.

TRANI, P.E. Hortaliças folhosas e condimentos. In: PEREIRA, M.E.; CRUZ, M.C.P.; RAIJ, B. van; ABREU, C.A. Micronutrientes e elementos tóxicos na agricultura. Jaboticabal: CNPq/FAPESP/ POTAFOS, p.293-310, 2001.

TRANI, P.E.; CARRIJO, O.A. Fertirrigação em hortaliças. Campinas: Instituto Agronômico, 2004. 58 p. (Boletim Técnico IAC, 196).

VALENTIN, M.A.A. Desempenho de leitos cultivados ("constructed wetland") para tratamento de esgoto: contribuições para concepção e operação. 210 f. Tese (Doutorado em Engenharia de Água e Solo) - Faculdade de Engenharia Agrícola, Universidade Estadual de Campinas, 2003. 